\title{
Cultural Dimension and Specificity of Public Governance
}

\section{Subject and purpose of the paper ${ }^{2}$}

More than 50 years ago, at the beginning of development of newly independent postcolonial states in Africa, the concepts of modern, efficient and participative public administration was already promoted by UN and bilateral cooperation in the field of public administration development in these countries. Later on, at the beginning of nineties, the new concept of "public governance" appeared first in the context of development strategies for so called "developing countries", and later on also for the post-communist "countries on transition".

The concept of "public governance" is putting accent on more interactive and participative mode of exercise of government functions, calling it "good -" and/or "democratic governance".

Progressively it became fashionable, commonly used and discussed on international level in different scientific milieus. The papers on this issue, presented during international conferences were showing the efforts to develop national public administration systems conform to the standards of an universal model of modern, good and democratic governance. At the beginning of $90^{\text {th }}$, this concept

1 Dr Witold Mikulowski is IIAS Vice-President for Eastern Europe and Vice-President of (Polish) Association for Public Administration Education (SEAP), wituka1@gmail.com.

2 This paper presents a new version of the papers consecrated to this issue presented in 2014 and discussed during the NISPAcee annual conference in Budapest and during IIAS Annual Congress in Ifrane (Marocco);

3 Logically, when we are using the term "good governance" we supposed also that this governance is not always necessarily good. Supposing also that a governance system (or function) in a particular country is participative and interactive, we are excluding the possibility that, despite being participative and interactive, it can remain, or became, inefficient and ineffective. 
has started to be promoted also in post-communist countries on transition from "socialist democracy" to western type liberal democracy.

This relatively new concept ${ }^{4}$ is based on the fundamental ideas and basic standards of well-developed democratic societies, their systems of values and corresponding attitudes and behaviours, as well as on cultural codes of their interpretation. From this time, anything which, in a country concerned, is not corresponding to these standards, is generally considered as a consequence of underdevelopment of its political and/or public administration systems. In certain countries and in some extent it can be true, but in many others it seems less evident.

Proposing this subject I was inspired by my own experience of international expert in the field of administrative reform. Working for more than 50 years in this field in different developing and transitional countries in Africa, Central and Eastern Europe, Central and South Asia, I have witnessed how cultural factors were, more or less strongly, but always significantly affecting governance relations and their outcomes. I am convinced that by its nature this subject is essentially interdisciplinary and requires participation and contributions of practitioners as well as researchers, specialists of social, economic and human sciences interested by this complex phenomenon.

In following developments I am discussing first the concept of public governance and its understanding in different disciplines. I am presenting next my reflexions on the role of cultural values in development of any public governance system in the context of criteria permitting to consider this governance as good. We should analyse this question referring to the examples of organization and functioning of concrete government systems in different particular countries, taking into account both their historical development and their present internal and external constraints. I am concentrating my attention mainly on the specific problems of present Polish governance system and on the perspectives of its farther development, trying to take into account the larger context of post-communist heritage of former soviet block countries.

\section{The role of cultural values in development of good public governance systems}

To identify and to recommend what need to be changed in view to make a public governance system in a concrete country more democratic and conform to modern good governance standards, can be consider relatively simple. However, to recommend how to do it and to conceive and implement a good strategy permitting to obtain expected or, at least satisfactory results, proved to be much more difficult. It is particularly difficult to find the way how to make this system not only more democratic, but also make it more efficient in ensuring a satisfactory level

4 The concept of "governance" was initially used in the field of management of big private companies. 
of living standards of its population and capable to ensure its farther sustainable development. It requires to define a good strategy of change, to formulate and adopt corresponding policies, programs and action plans for their implementation and to evaluate and mobilise necessary resources. It requires also a careful analyses and interpretation of different important and interdependent factors, explaining the nature and origins of weaknesses, failures and pathologies of present public governance system. These difficulties should be overcome if we want to ensure an improvement and further development, not only of its democratic character but also of its efficiency.

In the majority of developing as well as post-communist countries, despite the declarations of good will and apparent involvement of the governments concerned, despite also a big external financial support and technical assistance from abroad, the results obtained in this domain up to now, were often deceiving. We should conclude, that the problem lies not in formal acceptance of this set of basic values, considered as fundamental for our community of modern and democratic nations and their formal introduction in a country legal framework. It concerns more the understanding and interpretation of these general concepts, when applied in a concrete society, in a particular political and socio-economic situation and in the specific context of cultural values shared by the different actors of governance system which are influencing their way of thinking and behaviour.

The question is how these values affect and determine their interactions and attitudes in decision making and policy implementation processes. It seems obvious that, from this point of view, the situation is varying in different countries and depends of several factors of which, in my opinion, the most important are :

1. historical evolution of the country political identity and autonomy,

2. the level of its social and economic development,

3. its physical environment and natural resources, their international environment and

4. last but not least, its social and cultural specificity and complexity.

All this factors are interdependent and determining the priorities, constraints and capacity to conceive and implement a sustainable model of good governance, well adapted to the country needs as well as to its capacity to implement it successfully.

In my opinion, the country cultural specificity, which constitutes one of the most decisive factor of its faculty to have a good governance system, was not, up to now, sufficiently taken into account in our research and reflexion concerning this issue. Meanwhile, in each country, this factor strongly affects the social relations inside of government structures as well as their relations with its national and international environment. It is particularly important in developing and transitional countries, where, despite apparent similarity of common colonial or communist past, the role of this factor in each country is more or less complex and specific. In view to 
identify and to explain the role of this factor for public governance in a particular country, we should analyse the origins, specificity and evolution of the role of cultural factors in the governance system relations in each society concerned.

We should also keep in mind, that the culturally determined values have their hierarchical structure. Their hierarchy is changing in different social, economic and political context and is often different for different actors of governance processes. The situation is varying from existence of one strongly dominating culture shared by the majority of actors of the governance system of the country concerned, to a very complex social systems, where many different cultures are coexisting. In such a country these cultures are competing and mixing up at the country level or in its different regions, where they can have more or less strong position. Only knowing this specificity, we can perceive and analyse the influence exerted by this factor on the way of thinking, attitudes, behaviours and decisions making processes of different partners in governance activities and their respective role for their quality.

We should distinguish also different contexts in which this factor can affect behaviour and decisions and their principal actors of this process. The first of them concerns internal activities, interactions and relations between the different actors, inside different structures of governmental system and between their different levels. The second concerns its impact on the relations between public institutions and their stakeholders. It concerns, more particularly, the formal and informal relations between representatives of public authorities from one side and their individual and collective partners in the civil society, from another side. It includes also public authorities relations with private and third sector institutions (traditional authorities, social organisations, political parties, religious communities).

We should not forget also the question of mutual understanding and effective collaboration between national and foreign experts with different cultural background, executing together administrative and governance reforms projects.

The essence of the concept of governance lays in focusing the attention on the functions and processes (object) of governing, as well as on the subjects who are governing, are actively participating in the governance processes or are only governed. In a "democratic governance", the main accent is put on interaction, active participation and basic equality of all participating partners of governing processes. Therefore the efficiency of this function requires active participation of all actors concerned, shareholders and stakeholders, politicians, civil servants and citizens. A democratic governance is supposed also to be transparent for its shareholders as well as for its stakeholders.

However, the concept of good governance contains also another important dimension, namely its effectiveness and efficiency. We should not forget, that to be consider good, a governance system has to be not only democratic, but also effective and efficient. We should remember also that, in reality, not all democratic 
governance systems fulfil well automatically both of these conditions. From one side, we have a lot of examples of relatively democratic governance system, which are not very effective and efficient. For example, it happens often in many of the former "eastern block" countries in Central and Easter Europe. From the other side we have had also in our history, as well as we have presently, several examples of governance systems, which cannot be consider democratic, but are able to ensure economic, social and even cultural development of the country, sometimes even a significant improvement of the level of wellbeing of the majority, or at least a big part of their population. It is the case of certain rich Arab countries of Persian Gulf or, more recently, we are observing a significant and rapid progress in economic and social development of China.

Up to now, papers on this issue, presented during international conferences of International Institute of Administrative Sciences and different other international meetings, were showing efforts to develop national public administration systems conform to the standards of universal model of modern, good and democratic governance. This new mode, to express more democratic approach to traditional functions of government, was based on the ideas and standards of well-developed democratic societies, the systems of their basic values and corresponding attitudes and behaviours, as well as on cultural codes of their interpretation. Using this concept they seem to consider that governance cannot be good if is not democratic. From this point of view, everything which is not corresponding to these standards, is generally considered as a consequence of underdevelopment of political and public administration systems.

In many cases and in some extent it happens to be true. Actually, to identify and to recommend what need to be changed, in view to improve present public governance system, seems relatively easy. But, too define good strategies, to formulate and adopt corresponding policies, programs and action plans for their implementation is much more complicated. It requires a careful analyses and interpretation of different important and interdependent factors explaining the nature and origins of weaknesses, failures and pathologies of present governance system, which should be overcome in view to ensure its improvement and further development. We should also not forget human and financial resources necessary for implementation of the necessary changes, which need to be evaluate and mobilise.

However, to implement these strategies and to obtain expected results, using recommended forms and procedures of good governance, successfully practiced in well-developed western democracies, proved to be difficult. In the majority of countries, despite official declarations of the good will and apparent involvement of governments concerned, despite also a big external financial support and technical assistance from abroad, the results obtained up to now, were often deceiving.

In consequence, we can conclude, that the problem lies not in formal acceptance or rejection of these set of basic values, which were commonly recognised and 
consider as fundamental for our community of modern and democratic nations, but in the way we can implement them in practice. Actually, it concerns more the understanding and interpretation of these commonly accepted general concepts, when they are applied in concrete society, in particular political and socio-economic situation and in the context of cultural values shared by the different actors of governance system and influencing their way of thinking and behaviour. The question is how these values affect and determine their interactions and attitudes in decision making and policy implementation processes. It seems obvious that, from this point of view, the situation is varying in different countries and depends of several factors. The most important are :

- historical evolution of their political identity and autonomy,

- level of their social and economic development,

- their international political, social and economic environment,

- their social and cultural specificity and complexity.

Another very important and often neglected factor concerns the hierarchy of social values. Actually, it happens often that the actors directly concerned and sharing the same social values are confronted with the concrete situations where it's necessary to choose, which of these values is more important because they are conflicting if not excluding each other, because it is not possible, as it is expressed in one French expression "to have at the same time the butter and the money for butter" . It happens often, that even in the same general cultural environment, this hierarchy of values can vary in different social milieu and in particular, often culturally determined situation. All this factors are determining the priorities, constraints and capacity to conceive, implement and adapt to permanently changing constraints, a sustainable model of governance, well adapted to the country needs and limits of its capacity to implement it successfully.

In this context, the cultural specificity, which constitutes, in my opinion, one of the most decisive factor of development, was not, up to now, sufficiently taken into account in our research and reflexion concerning different public governance systems. Meanwhile, this factor strongly affects social relations inside of the government structures as well as their relations with their national and international environment. This is particularly important in developing and transitional countries, where, despite apparent similarity of common colonial and/or communist past, the role of this factor is in each country more or less complex and different.

In view to identify and explain the role of cultural factor of public governance in particular country, we should analyse the origins, specificity, evolution and present role of the culture of the society concerned. Doing this, we should keep in mind that cultural values have their hierarchical structure. Their hierarchy is changing in different social, economic and political context and is often different for various actors of governance processes. Their role and importance are varying from the 
situation of existence of one strongly dominating culture shared by the majority of actors of the governance system concerned, to a very complex social systems, where many different cultures influencing attitudes and behaviours of the actors of governance processes are coexisting and competing at the country level, or in its different regions where they can play more or less important role 5 . Only on this bases, we can perceive and analyse the influence exerted by this factor on the way of thinking, attitudes, behaviours and decisions making processes of different partners in governance activities.

We should also distinguish, different contexts in which this factor can affect behaviour and decisions of the principal actors of governance activities. The first one concerns internal activities, relations and interactions in different structures of governmental system and more particularly in politico-administrative relations. The second concerns its impact on the relations between public institutions and their stakeholders and especially, formal and informal relations between representatives of public authorities from one side and their individual "clients" from another side. It concerns also the relations of public authorities with their shareholders (private and third sector institutions like traditional authorities, social organisations, political parties, religious communities).

We should not forget also the question of mutual understanding and effective collaboration between national and foreign experts with different cultural background, conceiving and implementing together administrative and governance reforms projects.

In my opinion, the main questions, which need to be discussed are :

1. should we have one, universal model and common criteria of "good governance" fitting to every country world-wide?

2. can we have a democratic government without a voluntary, active and effective involvement of main actors supposed to participate in governance processes?

3. do we consider that a "good governance" has to be also "democratic" because the concept of "democracy" is universal and based on the same criteria for every country and society in the world independently of the stage and/profile of their social, economic and cultural development?

4. do we consider that only a democratic model of governance of western, well developed countries can be really efficient, or we consider that in some circumstances and more particularly in the context of weak development of the civil society concerned, certain form of less democratic or even non democratic governance

\footnotetext{
5 We have had a best example of this phenomenon during the last presidential elections. Looking on the map of the vote we can see an evident division of Poland into two parts, eastern half of the country, less developed, more rural and traditionalist, was voting for a conservative rightist candidate of present opposition and the western, more modern, more industrialised and less traditionalist and culturally diversified part of the country, for central wright candidate identified with governing coalition.
} 
systems can be, for the time being more efficient?

1. are we convinced, that such un universal model of good and democratic governance can ensure also its efficiency for a sustainable development and wellbeing of population in every country and at every stage of its social, economic and cultural development?

2. are we all really sharing, not only the same basic common values of "good governance" and their understanding, but also the same hierarchy of their importance, firstly with our reference models from well-developed democratic countries and secondly with all internal social and cultural components of our respective societies?

3. what we are doing, or how we are behaving in the situations of conflicts between different criteria of good and democratic governance and we have to choose, which one is more important and taken into account first in our everyday practice or in our strategic planning?

4. and, last but not least, do we consider also that the development of good governance requires a particular model of government, which should be necessarily democratic to be able to ensure an efficient governance?

\section{The origins and development of the concept of good and democratic governance}

From the very beginning of political transition in post-communist countries (starting in Poland already about 25 years ago in 1989), we are using more and more often in our political and academic discourse, the term of "governance" or "good governance" 6 . Our inspiration to use this concept came from divers sources, but mainly through the EU official documents, experience of foreign and international technical cooperation and various types of scientific relations with western, well developed countries (exchange programs, expertise, and international conferences like, among others, NISPAcee, EGPA and IIAS).

This relatively new concept constitutes in fact a kind of a next step in evolution of ideas relating the search for more active involvement of the civil society in the policy making and policy implementation processes. As the first step to the development of this concept we can consider beginning of 70-ties, when the notion of "consultative administration"7 was largely discussed. The second step of this evolution was development of citizens "participation" 8 in public administration.

\footnotetext{
${ }^{6}$ In our countries we have till now some difficulties and controversies how to translate the term "governance" in our language. In Poland it is often confused with the concept of "public management" (cf. for ex.

Cf. "La consultation dans l'administration contemporaine", Ouvrage collectif publie sous la direction de Georges Langrod, Ed. Cujas Paris, 1972, 971 p.

8 Cf. Chevalier J. Loschak D : «Science administrative, V.I Theorie generale de l'institution administrative », Ed. L.G.D.J Paris 1978 p. 362-366,
} 
The term of "democratic governance" as such appeared finally, in the beginning of nineties. In fact, this concept was formulated and promoted as a new approach to development policy in so called "developing countries" during the conference in Nairobi in 1995. I was personally involved then in one of the first application of this new approach to administrative reform as Chief Technical Advisor of UN OPS project "Program for capacity reinforcement of the Civil Service management" in Cameroun, renamed at this occasion as "Governance and Administrative Reform Program". In the post-communist countries, this concept was imported from welldeveloped democratic countries of western world, where it was built on the set of their common values and cultural codes of their interpretation, as well as on corresponding standards of attitudes and behaviours of "governance" process participants. Everything, which in our political, social, economic context and, last but not least, cultural environment, was not corresponding to these officially recognised and shared standards, was generally consider as pathology and/or sign of our institutional underdevelopment.

In certain cases and in some extent, it was true.

However, these distortions require a careful analyses, interpretation of concrete facts and explanation of their origins and social, political and economic consequences.

It is also obvious, that the general standards of "good governance" cannot be simply implemented by political declarations and adoption of legal acts. After all, very often, we have had them already in our "socialist" constitutions, but unfortunately, these nice legal principles were in practice not implemented, guaranteed and really protected. Actually, the question is not about acceptance or rejection of these set of basic common values, which we all consider and share as fundamental for our community of modern, democratic nations. It concerns rather the hierarchy of their importance, interpretation and modalities of their implementation and forms of protection in concrete situations. This hierarchy should be established, taking into account cultural, social and political constraints, as well as the specificity of their perception and the degree of their understanding and acceptance in the societies concerned.

We need also take into account the degree of internal social, economic and cultural specificity and diversity of each country. In fact, these values and hierarchy of their importance can be perceived differently even in different part of the same country and/or in its different social milieus. It seems particularly important, when we are confronted with the necessity to prioritise and choose, which one of these values is more important and/or urgent in concrete situation and, more particularly, in the case of their potential or real conflict. It concerns most often the competition for allocation of the financial resources for different types of activities in the central and local budgets. 
Therefore, adopting certain solutions, inspired by the examples taken from our external partners, and implementing them in our particular context, we need to take into account possible difficulties and consequences of their implementation in our specific social, economic, political and, last but not least, cultural context. We should also take into consideration, that different concrete solutions imported through different channels, from different western democracies and through different forms of scientific and technical cooperation, are often not coherent to each other, because each country has its own history and constraints of institutional and legal development of their governance model.

Actually, we need also take into consideration, that despite the fact, that all our West European partners are declaring to share basic common standards of western style democratic governance system, their institutional and legal framework of implementation are generally not the same or often even not very similar. In fact, the world of western democracies is composed of different legal cultures and traditions of institutional development of their governance systems (British Common Law and continental European Public Law systems). Each of them has its long historical development, based on a specific evolution of their political systems in different social, economic and geographic constraints and specific set and hierarchy of their cultural values. Each of them is facing also different problems and constraints of their further development. Therefore, the ideas and concrete solutions, brought from their particular context, through different channels of international and bilateral scientific exchanges and technical cooperation, does not necessarily fit well, or are not possible to implement effectively, as such, in our particular social, economic and cultural context 9

There are in fact, at least, three factors, which were, and in some extent still are, influencing the development of our governance systems after the fall of the Soviet Block.

1. The first one concerns the consequences, for governance systems of our different countries, of their own historical heritage and development of their political system before, during and after the fall of communist regimes.

2. The second one, concerns specific social and economic constraints, like type and degree of development of their economy, their ethnic composition and social structures, level of education, urban development, infrastructures etc... .

3. The third one, which more particularly interests us here, is their cultural identity, specificity and diversity, which are strongly related to the degree of internal homogeneity or heterogeneity of each of ours societies.

9 The phenomenon of copying solutions from other, more developed countries, by newly independent postcolonial states and its inadequacy to their specific context, was well known and described already many years ago under the name of "mimetism" (cf. Langrod G. : "Genese et cosequences du mimetisme administrative en Afrique" (in:) Revue International des Sciences Administratives, Brussels 1973, p. 119-132; 
All these factors were not, up to now, sufficiently taken into account in our research and discussions concerning our struggle for democratic and efficient governance model. All of them are strongly interrelated and can be more or less complex in different countries of our geographical zone. They are influencing and modifying each other during the country historical development and were subject of external influences of their dominating neighbours.

The problem I propose to study and to discuss here is the nature, role and importance of cultural factor for the development of each of our different countries' governance system, taking into account their strongly interrelated mix of political and cultural heritage and social and economic specificity. It should be analysed first taking into account different stages of evolution of their governance system, which, despite apparent similarity of common communist past, were in each country very different.

Actually, we should distinguish at least four dimension of the role of cultural factor.

The first one concerns its role in the functioning of political system of the country and its institutional framework, and more particularly, in government relations with its political environment in the process of determination of legal acts and policy documents, their application, follow up and evaluation.

At this level we should analyse the role of cultural context for the stability, continuity and coherence of the policy making and evaluation processes. Here the important question concerns the rationality, coherence and efficiency of adopted general legal framework (Constitution and main legislative acts) taking into account particular cultural constraints influencing the way of thinking, decision making process and attitudes of main actors of this system.

The second one concerns its influence through :

- largely understood international cooperation in the field of administrative reform processes, including collaboration of national and foreign experts of technical cooperation programs and projects,

- our participation in international research projects, study tours and scientific staff exchange programs;

- our membership and active participation in international organisations activities and more particularly in the framework of EU institutions.

The question here is about reception, transfers and coherence of different foreign "ready to use" concepts, models and even concrete, practical, but mainly legal solutions, without sufficient understanding and necessary adaptation to specific national context. This problem is particularly important when, from one side, the nationals don't know and/or understand well enough, the cultural context of the solutions they are transferring in their national context and, from other side, foreign expert don't know and understand well enough the specificity of cultural 
context and other constraints of beneficiary country (of which, generally, they don't understand even language and cannot read original legal documents).

The third aspect concerns cultural dimension of politico-administrative relations within public administration system itself and, more precisely between political appointees and professional, theoretically politically neutral, administrative level of decision making.

The last, but very important dimension, concerns the role played by cultural factor in the relations between public administration and its social and economic clients and stakeholders, which can vary in different part of the country and in different social milieu. In this last case, this factor plays a crucial role for public administration efficiency and on the level of what Fukuyama calls its "transaction costs" 10 , which are generated mainly by the mutual suspicion pushing one side to multiply precautions and unnecessary controls, delaying decision making process and from another side, suspicions concerning administrative decisions objectivity and honesty, which push to contest the decisions at different administrative and judicial levels, delaying their implementation and creating additional costs.

Generally speaking, specific historical development of governance systems should be considered mainly as a heritage composed of both positive and negative factors forming our way of thinking, attitudes and behaviours determining the relations between government and civil society. The negative factors should be considered as set of constraints to be taken into consideration, overcome and progressively eliminated and positive factors should be promoted and developed.

The cultural identity and specificity can be analysed and should be considered also as an important advantage, but under the condition, that the good governance is understood in its essence and not necessarily in the same forms of expression and an identic or similar legal framework, in which it is practiced in western democracies ${ }^{11}$.

The second question is how to identify certain practices and institutional settings of particular well developed European country, which are considered good and corresponding to democratic standards of western type democracies, but in the same time could be dysfunctional and not work correctly in post-communist countries. It wasn't easy choice and adopted solutions turned out to be not necessarily well adopted and fitting to particular country context.

In my presentation, I am concentrating my attention mainly on some aspects of cultural dimension in Polish governance system, which I consider have been

10 Cf. Fukuyama F. (1995). Trust: Social Virtues and the Creation of Prosperity and (2001). Social capital, civil society, and development. Third World Quarterly, 22(1): p. 7-20.

11 We should also remain here that also well-developed western type democratic governance system are not ideal in their respect of commonly shared standards and, from this point of view, each countries has its stronger and weaker points depending of their own traditions and specific constraints. 
playing important roles in formation of its present characteristics. In following developments I am trying to combine the diachronic and synchronic approach ${ }^{12}$ presenting two examples of their application.

The first one concerns the role of Polish electoral system and the second one the development of Polish Civil Service. In the following development I am trying to present first historical roots and the evolution of Polish governance system from the time of Second Republic, built after the $1^{\text {st }}$ world war, through "socialist" Poland after the world war II and its evolution during Third Republic created after the fall of communism.

After that, I am presenting the example of the influence of concepts and experiences of different models of civil service coming presently through different channels and processes of European integration and international organizations as well as through different forms of bilateral technical and scientific cooperation with well-developed democratic countries of western world.

\section{Historical origins of Polish governance system and their consequences for development of present governance system and of its cultural dimension}

\subsection{Short history of Polish governance system}

In Poland we have had first, a long history of 8 centuries of development of a big, independent, multi-ethnic and multicultural state, with mainly rural economy and commercial exchange based on the export of agricultural products, followed by more than hundred years ${ }^{13}$ of division and absorption by three different powerful neighbouring empires (Russian, Austro-Hungarian and Prussian).

Each of them have had a different culture, different model of governance and different policy towards integrated Polish territory. But, during last hundred year of this period, former Polish territories have had also more or less dynamic industrial and urban development in different part of our country ruled by different foreign authorities.

After the first World War, Poland has recovered its autonomy over a big part of its former territory and was successfully building a new modern independent and democratic state. But, after only less than 21 years, Poland has lost its independence once again, and was occupied during more than 5 years by 2 hostile and dictatorial superpowers - fascist Germany and communist Soviet Union. During this period

12 The concept of diachronic and synchronic approaches were proposed by Jacques Chevalier and Daniele Loschak in their excellent „Introduction a la Science Administrative „, (ed. Dalloz 1974)

13 More precisely from 1795 to 1918 Polish Kingdom was divided into 3 parts respectively, dominated and finally absorbed by the Russian, Prussian and Austrian empires (with short interval for rom 1805-18012 for reduced territory of Warsaw Principality during Napoleonian period). 
Polish capital city Warsaw was completely destroyed, country economy was ruined and has lost a big part of its elites killed, deported or fled abroad. However, Poland was able to build, under the occupation, an underground independent system of governance, trying to develop and maintain clandestine basic structures of our pre-war administrative system placed under the authority of the internationally recognised Polish government abroad (in London).

After the end of the 2ed World War Poland has formally recovered its independence, but in completely new frontiers and with imposed communist model of the state, with authorities rejecting any continuity with precedent model and with, in fact, strongly limited sovereignty as a communist block member. Poland has lost more than half of our pre-war territory from its eastern side, occupied already at the beginning of the war and integrated formally into Soviet Union in 1944. To compensate these loses, at the end of the war, Poland has received a new territories, on the west and north-east side, at the expense of another new socialist country East Germany. This modifications of frontiers has deeply changed ethnic, social, cultural and economic structures of the country. Poland has lost most of its ethnic and cultural minorities (Ukrainians, Lithuanians, Bielorussians, Jews and Germans). Most of Polish, biggest in Europe Jews population was killed by Germans and a big part of Polish population living in the part of the country lost on behalf of Soviet Union, was removed to the new Polish frontiers, including new western territories, completely emptied, by force, of their German natives and with most of industrial infrastructures destroyed during the war or deported to the Soviet Union. It has created in this new Polish "Far-West" a cultural melting pot composed of deracinated settlers (including number of Ukrainians removed from South-East part of our post war territory), building a quiet new society. We need to add to this picture another important factor changing social and cultural identity of post-war Poland, which was a very big loss of Polish elites, partly killed during the war, partly intentionally killed by Germans and Soviets, partly voluntarily did not return from Western Europe after the war, partly left Poland later, fleeing communist persecution.

Moreover, our social and economic structures were completely modified due to nationalisation of private enterprises, properties and bigger land ownership. Fortunately the efforts of total collectivisation of our peasants and nationalisation of our craftsmen was not completely achieved and finally failed. Nevertheless, all these events, have profoundly changed political and economic, as well as social and cultural composition of post war Polish society and its relations with imposed by force communist government. It has developed a particular, pathological type of mentality and behaviour inside of politico-administrative system, as well as in the civil society itself and its relations with the authorities, which up to now remain in subconscious of Polish mentality and continue to influence strongly the 
relationships with public authorities. Actually, for a big part of Polish population, public authorities are always considered as foreign enemy, despite the fact that they were elected through free, democratic and transparent elections.

From the other side, despite the fact that, in principle, Poland has really started to build again a new independent and western type democratic state only 24 years ago (in our new post-war frontiers), the processes of new institutional building, modernisation and even democratisation of Polish governance system, has started much earlier. Actually, the road from Stalinist model of communist government system to the western style democracy, started progressively already after the death of Stalin in 1955. The "defreeze" following the events of October 1956 has opened Poland to the western world and to the internal debates concerning a more democratic governance system. In 1968 this process was interrupted by political crises partly related to internal conflict and struggle for power within governing communist party, which has ended with forced emigration of important number of Polish elites, mainly those with Jewish roots. The next important stage of this process followed the social and political crises of 1981, which once again pushed an important part of our elites for forced or voluntary emigration. Despite the persecutions of political opposition immediately after these events, the new political authorities have permitted however a progressive development and introduction of important institutional reforms, which have prepared the ground for Polish bloodless revolution of 1989 and introduction of liberal-democratic model of governance in the country.

\subsection{Cultural dimension of Polish electoral system}

Following this radical, but smoothly conducted political change, we started once again to build our new institutions looking for the reference models in welldeveloped West European countries, hesitating often which one will fit better for Poland. This was, for instance, the case of electoral system in Poland, which is presently based on proportional model. This model is working correctly in many western democracies but in Poland (and probably in other post-communist countries) is certainly not, because is biased by the pathological practices of elections inherited from the former one party system. Actually in Poland, even if citizens have a choice between different parties, once they choose one list, they have to select just one name, out of the number of candidates on the list and, in this way, they are electing automatically others, even if they don't know them or not like them. In a particular post-communist context, this electoral system is unavoidably conducting to the "partitocracy" instead of real democracy, because victorious party or coalition behave seemingly like governing parties under communist rules, with strong tendency to change radically the policy conducted by their predecessors including changings in recently adopted legal framework. 


\subsection{Institutional development of Polish Civil Service and its different reference models}

The development of new model of Polish Civil Service presents a typical example of search for foreign inspiration in the process of creation of new democratic institution after the fall of communist regime. After a long 7 years of search and hesitations, it took first the inspiration from the French Civil Service model, neglecting its own tradition of the Civil Service model of the Second Polish Republic, despite the fact that this model proved to be very efficient before the war and during the war (under the occupation) and was finally abolished only in 1974.

The first explanation, why Poland didn't returned to its proper tradition, when this possibility existed after the fall of communist system was, that the civil service regulations, were abolished and replaced by general Labour Code prepared with the technical assistance of ILO experts. In consequence, the field of public employment became occupied by the lobby of Labour Law specialists who didn't know and understand the basic concepts and importance of the Civil Service based on a Public Law approach. The Public Law specialists at that time, were not involved and they didn't want or couldn't defend the own Polish tradition in this field.

The second reason was, that the basic foundations and legal framework of a Civil Service Law has been, in fact already created and implemented before the end of communist rule in 1982. However this legislation was taint of two important faults. The first one was psychological: this quasi Civil Service was introduced by the military regime of general Jaruzelski, just after the crackdown against democratic protests of 1981. The second one has had more political justification. Actually the new, post-communist authorities, wanted to clean up the administration from the supposedly communist cadres in view to have free hands to hire the new and more politically correct ones. Therefore, they decided to keep existing legislation in this field for a time necessary to prepare a new and more democratic one, but cutting out all its guaranties protecting civil servants against arbitrary firing.

Finally, the first law establishing a new civil service system, strongly influenced by the French Civil Service model but its application was restricted only to the governmental administration, was adopted 7 years after the fall of communist regime in 1996. However, very rapidly, not even two years later, in 1998 a quiet new Civil Service Law was adopted by the newly elected government based on opposition parties. It was founded on quiet different approach inspired rather by the German model of Civil Service system. This new legal framework was deeply modified, once again two times by new governments, first time in 2006 then second time in 2008.

Paradoxically, none of these law was referring to our own Polish model of Civil Service Law of 1922. Paradoxically, it was the law of 82, adopted well before the end of communist regime, which was much closer to its original Polish model 
and, from certain points of view, was more democratic and progressive than the new poste-communist legislations. It has for instance introduced important participatory elements in civil service management, which has disappeared from post-communist legislations.

Finally, presently standing civil service regulations, concerning both its legal status and institutional framework of its management, are far to be considered as perfect and well adapted to present Civil Service situation and need to be revised once again as soon as possible.

\section{Final conclusions}

The main purpose of this paper was to propose a new field of research in view to explore the issues of cultural dimension of public governance system and of the role of culture for its present functioning and future development. I am giving here only two examples of this very complicated issue, which certainly requires much more deep analyses of preferably an interdisciplinary team, composed of sociologists, psycho-sociologists, anthropologist as well as specialists of political science, policy studies, public management and administrative science.

However this interdisciplinary collaboration requires first a common understanding of the terms and concepts used to describe the phenomenon, which they were studying and analysing up to now separately, starting with the notion of public governance itself. Actually, this fashionable concept without giving its definition and is often understood differently by the representatives of different disciplines and often confused with the notions of government, public management and public policy.

\section{Bibliography (selection)}

Harrison L.E. \& Huntington S.P. (ed.) : Culture matters. How Values Shape Human Progress. (Basic Books USA, 2000, Ed. Zysk \& S-ka Poznan 2003 (Polish translation).

Inglis Ch. : Multiculturalisme : New Policy Responses to Diversity, Management of Social Transformations, UNESCO Policy Papers 4, 1996.

Kiezun W. : Management in Socialists Countries. URSS and Central Europe, Walter de Gruyter, Berlin - New York, 1991.

Sharing Best Practices in Introducing and Teaching Ethics Principles to Public Administration Employees. Research Report. National School of Public Administration (KSAP), Warsaw - Poland, Berlin School of Economics and Law (RFA - Berlin) General Directorate of Public Administration and Employment - INA (Portugal), Pub. KSAP, 2013 (in Polish).

Manning N. McCourt W. (red.) : La strategie de gestion du secteur public de la Banque Mondiale , Revue Internationale des Sciences Administratives (Numero special) Vol. 79 nr. 3 Septembre 2013. 
Zybala A. (red.) : Between Ideas, Interests and Institutions. Public Policy in practice - Science of "Overcoming Difficulties" (in Polish, English Summary) Zoon Politikon 2013 (4), Warsaw.

Mikulowski-Pomorski J.: Intercultural Communication. Introduction (in Polish). Ed. Academy of Economy, Cracow 1999. 